\title{
Unemployment Benefits and the Persistence of European Unemployment
}

\author{
Salvador Ortigueira* \\ Cornell University
}

October 21, 2001

\begin{abstract}
In this paper, we present a model of labor search in order to assess the role played by unemployment benefits in the increase of European unemployment since the mid 70's. Our main finding is that although benefits may reduce unemployment, they increase the vulnerability of the economy to employment shocks, which may result in a permanent increase in the rate of unemployment. The novel ingredient in our analysis is the simultaneous consideration of capital investment decisions and time allocation decisions. In so doing, we take into account the feedback between economic growth and unemployment. The predictions of our model provide some rationale for patterns in unemployment, capital accumulation and growth rates observed in some European countries.
\end{abstract}

Keywords: Frictional Unemployment; Economic Growth; Unemployment Benefits; Unemployment Persistence.

JEL Classification Numbers: E24; J64; J65.

\footnotetext{
*Department of Economics, Uris Hall 482; Ithaca, NY 14850. E-mail: so37@cornell.edu. I want to thank Juan José Dolado for conversations on European unemployment, and Nigar Hashimzade for helpful research assistance.
} 


\section{Introduction}

In this paper, we present a model of labor search in order to assess the role played by unemployment benefits in the increase of European unemployment since the mid 70's. Our main finding is that although benefits may reduce unemployment, they increase the vulnerability of the economy to employment shocks, which may result in a permanent increase in the rate of unemployment. The novel ingredient in our analysis is the simultaneous consideration of capital investment decisions and time allocation decisions. In so doing, we take into account the feedback between economic growth and unemployment. The predictions of our model provide some rationale for patterns in unemployment, capital accumulation and growth rates observed in some European countries.

The evolution of unemployment rates in Europe since the 60 's has posed a number of questions that have challenged most extant theories of unemployment determination. European unemployment experienced a transition from rates in the order of $1-2 \%$ in the early 60 's to rates in the order of $10-15 \%$ in the late 90 's. The increase in unemployment started in the mid 70's, and it stabilized at the current rates by the late 80's [see Figure 1]. This rise in unemployment has been interpreted by some authors as an increase in the natural rate of unemployment; that is, a switch from one steady-state equilibrium with low unemployment to another with high unemployment. Furthermore, this switch could have been provoked by the shock that hit most developed economies in the mid 70's, and not by policy changes. This has led to the conclusion that economic fundamentals cannot pin down the natural rate of unemployment, or, equivalently, that there exist multiple natural rates of unemployment.

Several attempts to explain why economic systems can generate multiple steady-state equilibria with different rates of unemployment have already been made. Blanchard and Summers (1986) have emphasized the role played by the wage determination mechanism in generating multiple equilibria. In particular, they use a model where wages are bargained with insiders, and show how multiple equilibria arise. Explanations based on the existence of increasing returns in production or in the matching function have also been proposed [see Mortensen (1999), and Mortensen (1989) for a review of this literature]. Pissarides 
(1992) suggests that the important mechanism arises from the loss of worker's skills during the unemployment spell. The explanation advanced by Saint-Paul (1995) stresses labor market distortions, more specifically, firing restrictions. More recently, Acemoglu (2000) has shown how the existence of credit market imperfections can generate multiple natural rates of unemployment.

In this paper, we provide a new explanation which relies on the existing, internal feedback between unemployment and growth. That is, we show that in a multisector economy with frictional unemployment the process of allocating inputs naturally generates multiple long-run equilibria with different rates of growth and unemployment. Although the evolution of growth rates in European economies since 1960 shows an unambiguous relation with unemployment, previous literature has largely overlooked this relationship as a source of hysteresis in unemployment. As we show below, like unemployment rates, per capita income growth rates also experienced a transition, moving from annual rates in the order of $5-6 \%$ to rates in the order of $1-2 \%$. Our analysis of structural breaks in growth rates shows that the transition started with the increase in unemployment in the mid 70 's.

In order to illustrate our mechanism for multiple balanced growth paths, we present a standard, representative-household model with physical and human capital accumulation and frictional unemployment. Our strategy is to simplify the model as much as possible, especially along those dimensions which are not needed for multiplicity. Thus, the main ingredients in our model are the endogenous determination of savings and the allocation of family members across economic activities -including income and non-income related activities. The key feature in our model is that human capital is a state variable attached to a worker only when at work. In other words, human capital affects the productivity of time allocated to goods production, but does not affect the productivity in any other activity, including labor search. Since this differential in productivity affects the current allocation of time across activities, which, in turn, determines the magnitude of the future differential, there is room for multiple long-run equilibria. Hence, depending on the initial differential, which is given by the composition of initial wealth -physical capital, human capital and employment- the economy will converge either to a long-run equilibrium 
with high growth and low unemployment, or to an equilibrium with low growth and high unemployment. In this model with two stable equilibria, an exogenous shock to employment (therefore to unemployment) may result in a shift from one equilibrium to the other. The magnitude of the shock needed to provoke this switch gives a measure of the vulnerability of the initial equilibrium.

We will use this model to assess to what extent unemployment benefits may have contributed to the increase in European unemployment. Here we ask the following questions: How do unemployment benefits affect the long-run rates of growth and unemployment? Do unemployment benefits increase the vulnerability of the economy to employment shocks? Why did the shock of the mid 70's not result in the U.S. in a switch to an equilibrium with high unemployment as happened in Europe? In order to answer these questions we first solve the model with no benefits. Then we calibrate the model so that the high-growth, low-unemployment equilibrium matches some key U.S. observations, and compute the vulnerability of this equilibrium to shocks. Finally, we introduce unemployment benefits and study the implications for both equilibrium levels and equilibrium vulnerability. The way in which we introduce unemployment benefits captures most of the salient features of unemployment programs in European countries. Namely, benefits to the unemployed decrease with the unemployment spell, and funds for the unemployment benefits budget are collected through distortionary taxes.

We obtain two main results from this exercise. First, unemployment benefits may increase the rate of growth and decrease the rate of unemployment. Second, unemployment benefits increase the economy's vulnerability to shocks. These results conform with the evolution of growth and unemployment rates observed in Europe and the U.S. The first result may explain why European countries, which have always had generous unemployment benefits, experienced a faster growth and a lower unemployment than the U.S. before the shock of the mid 70's. The second result explains why this shock affected both economies differently. Hence, the main conclusion we draw from this exercise is that unemployment benefits, by increasing the vulnerability of the economy to shocks, are ultimately responsible for the high unemployment in European economies.

The approach adopted in this paper, based on the interaction between shocks and in- 
stitutions, has been empirically validated by different authors [e.g., Blanchard and Wolfers (2000), Balakrishnan and Michelacci (2001)]. The evidence presented in this literature indicates that differences in unemployment dynamics in Europe and the U.S. are due to a different reaction to the same shocks rather than to exposure to different shocks. Moreover, labor market institutions seems to lie at the heart of this differential in the response to common shocks. At a theoretical level, the role of shocks and institutions has been assessed by Den Haan et al. (2001) and Ljungqvist and Sargent (1998). Although the margins through which labor market institutions shape the economy's response to shocks explored by these authors are completely different from those explored in our paper, their conclusions are, however, similar to ours. The main contribution of our paper to this literature is twofold. First, we present a new explanation of unemployment hysteresis. Second, we identify a new margin through which labor market institutions exacerbate the persistence of employment shocks. To our knowledge, this is the first paper that tackles the European unemployment puzzle in a model of capital accumulation, and where the growth rate and the unemployment rate are endogenously determined. The predictions of our model are consistent both with the evolution of key economic variables in European countries and the observed variation across Europe and the U.S.

The paper is organized as follows. Section 2 presents the evolution of growth and unemployment rates in Europe and the U.S. for the last four decades. In Section 3 we introduce our model, show the existence of multiple balanced growth paths and study the equilibrium dynamics. Section 4 contains our analysis of unemployment benefits. Section 5 concludes, and Section 6 contains the Appendix.

\section{Unemployment and Growth in Europe and the U.S.}

In this section we present data on unemployment and growth for a selection of European countries ${ }^{1}$ and the U.S. Our data consist of annual unemployment rates for the period 1960-2000, and annual growth rates of income per capita for the period 1960-

\footnotetext{
${ }^{1}$ Our selection of European countries includes: Belgium, Denmark, France, Germany, Greece, Ireland, Italy, Netherlands, Portugal, Spain, Sweden and United Kingdom.
} 
1997. We take unemployment data from the OECD Economic Outlook, and compute the growth rates using data on GDP per capita in 1990 dollars. In Figure 1 we plot the unemployment rate for the U.S. and the average unemployment rate for our twelve European countries. There are three features that should be noted: First, until the mid 70's unemployment was much lower in Europe than in the U.S. Second, the increase in European unemployment of the mid 70's set off a decade of increase in unemployment. After that decade, unemployment did not return to pre-shock levels. Third, the shock to U.S. unemployment in the mid 70's was much less persistent than in Europe. U.S. unemployment had returned to pre-shock levels by the late 80 's.

The evolution of growth rates in Europe and the U.S. is now presented. Before the mid 70's, growth rates in Europe were higher than in the U.S. The shock of the mid 70's yielded negative growth rates both in Europe and the U.S. However, contrary to what happened in the U.S., growth rates in Europe did not return to pre-shock levels. An example of this is shown in Figure 2, where we plot unemployment and growth rates for France and Spain. In this figure, it can be seen that there is a structural break in growth rates in the mid 70's, and that the date of the break coincides with the increase in unemployment rates. Similar patterns are observed for the other European countries considered in this paper. Table 1 presents results of the test for structural breaks in growth rates for our selection of countries ${ }^{2}$. In the second column we present the year in which the break occurred. The third column shows the average growth rate before the break, and the fourth column shows this rate after the break. For all countries except Ireland a break was detected either in 1974 or 1975. The decline in average growth rates after the break was important, especially in France, Greece, Italy, Portugal and Spain. The break in Ireland occurred in 1984, and had the opposite sign; after 1984 the average growth rate went up to a $5.2 \%$. By contrast, we did not find a break in U.S. growth rates.

\footnotetext{
${ }^{2}$ Our test for structural breaks consists in regressing growth rates against a constant plus a time-period dummy. We say that a break occurred when the coefficient in the dummy variable is significative at a $5 \%$ level.
} 
Table 1. Structural breaks in growth rates

\begin{tabular}{llcc}
\hline \hline Country & Break & $\begin{array}{c}\text { Average growth rate } \\
\text { before the break }\end{array}$ & $\begin{array}{c}\text { Average growth rate } \\
\text { after the break }\end{array}$ \\
\hline Belgium & 1975 & 0.042641 & 0.016873 \\
Denmark & 1974 & 0.035312 & 0.019851 \\
France & 1974 & 0.042595 & 0.014986 \\
Germany & 1975 & 0.035217 & 0.019584 \\
Greece & 1974 & 0.068416 & 0.014606 \\
Ireland & 1984 & 0.031034 & 0.052742 \\
Italy & 1975 & 0.046208 & 0.018584 \\
Netherlands & 1975 & 0.034815 & 0.016257 \\
Portugal & 1974 & 0.066441 & 0.020556 \\
Spain & 1975 & 0.061492 & 0.015975 \\
Sweden & 1975 & 0.032915 & 0.011939 \\
United Kingdom & 1974 & 0.031054 & 0.014142 \\
United States & no break* & & \\
\hline \hline
\end{tabular}

${ }^{*}$ no break was found at $5 \%$ level.

\section{The Model}

Our economy draws upon the standard labor search model with frictional unemployment. There is a matching technology that determines the number of job matches per unit of time as a function of the number of unemployed workers and the number of vacancies. We adopt here the common assumption of a concave, linearly homogeneous and increasing matching function [see Blanchard and Diamond (1989) and Pissarides (1986)]. In particular, we assume the following matching technology,

$$
M(t)=M v(t)^{\eta} u(t)^{1-\eta}
$$

where $M(t)$ is the number of matches, $v(t)$ is the number of vacancies, and $u(t)$ is the number of unemployed workers; $M>0$ and $0<\eta<1$ are parameters. This technology 
implies that unemployed workers switch to employment according to a Poisson process with rate $M\left(\frac{v(t)}{u(t)}\right)^{\eta}$, and vacancies are filled according to a Poisson process with rate $M\left(\frac{v(t)}{u(t)}\right)^{\eta-1}$. The ratio of vacancies to unemployed workers, $\frac{v(t)}{u(t)}$, is the measure of tightness in the labor market.

We now embed this model of frictional unemployment in a standard endogenous growth model in which the number of unemployed workers, and the vacancies are determined by a household sector and a firms sector, respectively.

\section{Households}

There is a continuum of identical families in the economy. Each family has a continuum of members of measure one. We assume that there is perfect risk sharing within the family, so consumption is identical across family members. Each family member has one unit of time per period that can be allocated to only one of the following activities: leisure, home production, labor search, work in the firms sector, or education. Agents derive utility from consumption and leisure according to the following utility function,

$$
\int_{0}^{\infty} e^{-\rho t}\{\gamma \log C(t)+(1-\gamma) \log L(t)\} d t
$$

where $C(t)$ is the sum of market goods consumption, $c(t)$, and the home-produced goods consumption, $c_{h p}(t)$; and $L(t)$ is leisure. ${ }^{3}$ The technology in the home sector is assumed to be linearly homogeneous in qualified labor, that is, $c_{h p}(t)=A_{2} l(t) h(t)$, where $l(t)$ is the fraction of family members engaged in home production, $h(t)$ is the stock of human capital, and $A_{2}>0$ is a constant.

The family supplies the firms sector with physical capital, $k(t)$, and labor services. Labor services are measured in efficiency units as the product of the number of employed family members, $n(t)$, and the stock of human capital or skills accumulated by the family, that is, $n(t) h(t)$. The budget constraint of the family implies that,

$$
c(t)+\dot{k}(t)=r(t) k(t)+\omega(t) n(t) h(t)+\pi(t)
$$

where $r(t), \omega(t)$ and $\pi(t)$ denote the rental price of capital, the wage rate and the flow

\footnotetext{
${ }^{3}$ Our assumption of perfect substitutability between market and home-produced consumption is supported by estimates using aggregate data [see Eichenbaum and Hansen (1990)].
} 
of profits, respectively. If we denote the rate at which an unemployed worker is matched with a firm by $m(t)$, the total flow of job matches is given by $m(t) u(t)$, where $u(t)$, as stated above, is the fraction of unemployed workers in the family. There is an exogenous rate of job destruction, denoted by $\lambda$. Thus, the evolution of employment within the family is given by

$$
\dot{n}(t)=m(t) u(t)-\lambda n(t)
$$

Investment in human capital is possible through education. If $e(t)$ is the fraction of family members in the school sector, the law of motion for the stock of human capital is

$$
\dot{h}(t)=B e(t) h(t), \quad B>0
$$

The family's problem is therefore to choose sequences for $c(t), c_{h p}(t), L(t), l(t), u(t)$ and $e(t)$ in order to maximize the lifetime utility, (3.2), subject to the law of motion for $k(t), h(t)$ and $n(t)$; the restriction that imposes that all family members be engaged in some activity, $L(t)+l(t)+n(t)+u(t)+e(t)=1$; and $c_{h p}(t)=A_{2} l(t) h(t)$. Even though the matching rate, $m(t)$, depends on market tightness, $\frac{v(t)}{u(t)}$, our assumption of competitive behavior implies that the representative family takes this rate as given.

The first-order conditions for the household problem are presented in the Appendix. These conditions establish the optimal allocation of family members across competing activities, and the allocation of income between consumption and investment.

If $W(t)$ denotes the income value of an occupied job for the family, it follows that

$$
r(t) W(t)=\omega(t) h(t)-(m(t)+\lambda) W(t)+\dot{W}(t) .
$$

[See the Appendix for a derivation of this arbitrage condition.]

Firms

Firms hire physical capital and labor services from the household sector, and produce according to the constant returns to scale, CES production function,

$$
F[k(t), n(t) h(t)]=A\left(\alpha k(t)^{\sigma}+(1-\alpha)(n(t) h(t))^{\sigma}\right)^{\frac{1}{\sigma}}
$$


where $A>0$ and $0<\alpha<1$; since the elasticity of substitution is given by $\frac{1}{1-\sigma}$, we impose $\sigma<1$. In order to contact unemployed workers the firm must post vacancies. If we denote the rate at which a vacancy is matched with an unemployed worker by $\mu(t)$, and the number of vacancies by $v(t)$, then $\mu(t) v(t)$ is the total flow of matches. In order to simplify the analysis, we assume that firms post a constant and exogenous number of vacancies per period, say $\hat{v}$, and we also assume that there are no costs associated to the posting of these vacancies. It is important to notice that the assumption of an exogenous number of vacancies does not affect any of our results. In Section 4.2 we endogenize the determination of vacancies and show that the same results hold.

Given the exogenous rate of job destruction, $\lambda$, the evolution of employment in the firm is

$$
\dot{n}(t)=\mu(t) \hat{v}-\lambda n(t)
$$

Thus the current flow of profits is given by,

$$
\pi(t)=F[k(t), n(t) h(t)]-(r(t)+\delta) k(t)-\omega(t) n(t) h(t)
$$

The objective of the firm is to maximize the present discounted value of future profits. Hence, the firm demands physical capital in order to maximize,

$$
\int_{0}^{\infty} e^{-\int_{0}^{t} r(z) d z} \pi(t) d t
$$

The first-order condition for profits maximization is then

$$
r(t)+\delta=F_{k}[k(t), n(t) h(t)]
$$

where $F_{k}(\cdot, \cdot)$ denotes the derivative of the production function with respect to $k$.

So, if $J(t)$ denotes the income value of a filled job for the firm, it follows that

$$
r(t) J(t)=\left(F_{n h}[k(t), n(t) h(t)]-\omega(t)\right) h(t)-\lambda J(t)+\dot{J}(t)
$$

where $F_{n h}(\cdot, \cdot)$ denotes the derivative of the production function with respect to labor in efficiency units, $n h$. 


\section{Wage determination}

We follow here the standard assumption in the literature of frictional unemployment regarding wage determination. A realized job match yields pure economic rents which have to be divided between the firm and the worker. The wage rate is then the Nash solution to a bargaining problem. The Nash solution maximizes the weighted product of the worker's and the firm's return from the job match. If we denote the weight of the worker's return by $p$, then the wage rate is,

$$
w(t)=\arg \max \left\{W(t)^{p} J(t)^{1-p}\right\}
$$

Typically, $p$ is interpreted as the worker's bargaining power, and it is associated with labor market regulations. The first-order condition to problem (3.13) is

$$
p J(t)=(1-p) W(t)
$$

Using equations (3.6) and (3.12), and the fact that $\dot{J}(t)=\dot{W}(t)$, the wage rate is then given by

$$
\omega(t)=p F_{n h}[k(t), n(t) h(t)]+(1-p) A_{2} .
$$

If $p=1$, the worker gets the total income generated by the match; if $p=0$ the firm pays the worker's reservation wage. ${ }^{4}$

\section{Equilibrium}

We can now define a search equilibrium as a set of sequences for quantities, $\left\{c(t), c_{h p}(t)\right.$, $k(t), h(t), L(t), l(t), u(t), n(t), e(t)\}$, prices $\{r(t), \omega(t)\}$, profits $\{\pi(t)\}$, and matching rates $\{m(t), \mu(t)\}$, such that:

(i) Taking prices, profits and the matching rate $m(t)$ as given, the tuple of quantities solves the household problem.

(ii) Taking prices as given, $\{k(t)\}$ solves the problem of the firm.

\footnotetext{
${ }^{4}$ Notice that the constancy of the reservation wage arises from our technology in the home production sector. This property of the reservation wage will not affect any of our results, but will simplify the analysis considerably.
} 
(iii) Markets clear, and the wage rate is given by (3.15).

(iv) The matching rates are given by the matching technology, that is $m(t)=M\left(\frac{\hat{v}}{u(t)}\right)^{\eta}$ and $\mu(t)=M\left(\frac{\hat{v}}{u(t)}\right)^{\eta-1}$.

As is well known in this literature, there are searching externalities which may render the market equilibrium non optimal. These externalities spring from the effect that each individual's search has on the matching rate of other searchers. It should be noted, however, that these searching externalities do not play an active role in our subsequent analysis.

\subsection{Unemployment and Growth in the Long-run Equilibrium}

A balanced growth equilibrium is defined as an equilibrium solution along which $k(t), h(t), c(t)$ and $c_{h p}(t)$ grow at constant rates, and time allocations variables remain constant. It follows from the law of motion for $k(t)$ and the technology in the home sector that if such an equilibrium exists then both capital stocks and consumptions must grow at a common rate, that is, $\frac{\dot{k}(t)}{k(t)}=\frac{\dot{h}(t)}{h(t)}=\frac{\dot{c}(t)}{c(t)}=\frac{\dot{c}_{h p}(t)}{c_{h p}(t)}=g$. When $g>0$ the balanced growth path is said to be interior, if $g=0$ it is said to be non-interior.

In this section, we show that our model may display multiple balanced growth paths with different rates of growth and unemployment. As was stated above, the crucial feature in our model that generates the multiplicity result is the asymmetric effect of human capital across activities. The productivity of time devoted to goods production (home production, human capital production and output production) depends on the current level of human capital. On the contrary, the productivity of time devoted to activities not directly related with the production of goods (leisure and labor search) does not depend on human capital. Since human capital is a state variable that may evolve over time, this asymmetry yields complementarities between the current allocation of time and the value of human capital. The economic forces at work in generating such complementarities can be stated as follows. Suppose that, for a given level of employment, there is a high initial level of human capital. Since human capital increases the productivity of time allocated to education but not the productivity of time allocated to search, the family 
is relatively more efficient in the schooling sector, and therefore there will be more time allocated to the production of new human capital, and less time to search. As a result, unemployment will be initially low and the economy will converge to a balanced growth path with high economic growth and low unemployment. On the contrary, if the initial stock of human capital is low, then the family is relatively more efficient in job searching, and more time will be allocated to search and less to education. Thus, the equilibrium will converge to a balanced growth path with low or no growth and high unemployment. The same kind of argument could be elaborated by fixing the initial level of human capital and varying the initial level of employment, $n$. It should be noticed that the multiplicity of balanced growth paths in our model arises under concave matching and production functions. Contrary to other models of unemployment hysteresis [e.g., Mortensen (1999), Hart (1982) and Howitt and McAfee (1987)] we do not rely on increasing returns on matching or production.

These complementarities may yield aggregate dynamic non-convexities, and therefore multiple balanced growth paths. In order to show more neatly how the complementarities stated above translate into non-convexities in the family's maximization problem, let us temporarily concentrate on the case in which $p=1-\eta$. We concentrate on this particular case for the sake of expositional clarity, but it should be clear that the argument goes equally through when this condition does not hold. As shown by Hosios (1990) and others, when $p=1-\eta$ the two search externalities operating in this model cancel out. Hence, the market equilibrium is socially efficient, which implies that we can solve the market's problem by solving a planner's problem. After defining the variables, $h_{l}=l h, h_{L}=$ $L h, h_{u}=u h, h_{e}=e h$ and $h_{n}=n h$, the planner's problem can be written as follows,

$$
\begin{array}{ll}
\max & \int_{0}^{\infty} e^{-\rho t}\left(\gamma \log \left(c+A_{2} h_{l}\right)+(1-\gamma) \log \left(\frac{h_{L}}{h}\right)\right) d t \\
\text { s.t. } & \dot{k}=F\left(k, h_{n}\right)-\delta k-c \\
& \dot{h}=B h_{e} \\
& \dot{h}_{n}=M \hat{v}^{\eta} h_{u}^{1-\eta} h^{\eta}-\lambda h_{n}+B h_{e} \frac{h_{n}}{h} \\
& h_{l}+h_{L}+h_{u}+h_{e}+h_{n}=h \\
& k_{\mathbf{0}}, h_{\mathbf{0}} \text { and } h_{n_{0}} \text { given. }
\end{array}
$$


Since $\log \left(\frac{h_{L}}{h}\right)$ and $\frac{h_{n}}{h}$ are convex functions in $h$, the concavity of the planner's maximization problem is not guaranteed and, consequently, there may exist multiple balanced growth paths. At this point we can already anticipate that if the balanced growth path is not unique, there must be an odd number of such paths. More precisely, given the structure of our model the maximum number of stationary solutions is three, where one of them is non interior. Under uniqueness, the stationary solution can be either interior or non interior. We want to emphasize that the existence of multiple balanced growth paths in our model is due to differences in the productivity of time across activities. Our result does not rely on increasing return to scale in production or matching.

We now turn to our model presented in the previous subsection without introducing any restriction on parameters $p$ and $\eta$. We begin by imposing balanced growth path conditions on the set of equations that characterize a search equilibrium. After defining $x \equiv \frac{n h}{k}$ and $q \equiv \frac{c}{k}$, interior balanced growth paths are characterized by the following conditions.

The relationship between employment and market tightness, the Beveridge curve, is

$$
\lambda n=M_{0} \hat{v}^{\eta} u^{1-\eta}
$$

The wage rate is given by,

$$
\omega=p(1-\alpha) A\left[\alpha x^{-\sigma}+(1-\alpha)\right]^{\frac{1-\sigma}{\sigma}}+(1-p) A_{2}
$$

From the law of motion for physical and human capital we obtain, respectively,

$$
\begin{aligned}
& g=A\left[\alpha+(1-\alpha) x^{\sigma}\right]^{\frac{1}{\sigma}}-\delta-q \\
& g=B(1-L-l-u-n) .
\end{aligned}
$$

The Euler equation yields,

$$
\rho+g=\alpha A\left[\alpha+(1-\alpha) x^{\sigma}\right]^{\frac{1-\sigma}{\sigma}}-\delta
$$

Finally, the allocation of family members across activities gives the following conditions,

$$
M_{0} \hat{v}^{\eta} u^{-\eta}\left[\frac{\omega}{A_{2}}-1\right]=\rho+\lambda
$$




$$
\begin{gathered}
\frac{B}{A_{2}} \omega n=\rho-B l \\
q=A_{2}\left[\frac{\gamma}{1-\gamma} L-l\right] \frac{x}{n} .
\end{gathered}
$$

The system of equations (3.16)-(3.23) is not block-recursive and then it must be solved simultaneously.

Even though it is difficult to obtain precise conditions for the existence of multiple balanced growth paths, we can however provide some results on the behavior of our economic variables across interior balanced growth paths.

Proposition 2.1: Assume that there are two interior balanced growth paths, then:

(1) The balanced growth path with a higher growth rate has a lower unemployment rate.

(2) The balanced growth path with a higher unemployment rate has higher unemployment duration.

(3) The balanced growth path with a higher unemployment rate has a lower labor-capital ratio.

Proof: See the Appendix.

The set of parameter values for which the model yields multiplicity of balanced growth paths is fairly large. In order to carry out the quantitative experiments reported in the next sections, we set parameter values as follows. A first set of parameters is taken from the literature. The worker's share in the bargaining process is set at 0.5 . The scale parameter of the matching function is set equal to one; and the elasticity of matching with respect to unemployment is 0.475 . A second set of parameters is chosen so that the interior, saddle-path stable equilibrium of the model matches the following facts of the U.S economy: An average growth rate of income per capita of $1.8 \%$; a capital share of 0.36 ; a capital-output ratio of 2.8; an investment rate of $20 \%$; an allocation of time to market activities of $30 \%$; and an average unemployment duration of three months. Remaining parameter values are set in order to obtain the multiplicity result. Our baseline economy is presented in Table 2. 
Table 2. Baseline parameter values

\begin{tabular}{llll}
\hline \hline Matching elasticity & $1-\eta=0.475$ & Rate of capital deprec. & $\delta=0.055$ \\
Discount factor & $e^{-\rho}=0.946$ & Job destruction rate & $\lambda=0.1$ \\
Vacancies & $\hat{v}=0.085$ & Elastic. of subs. & $(1-\sigma)^{-1}=1.1$ \\
Worker's share & $p=0.5$ & Consumption share & $\gamma=0.435$ \\
Scale parameters & & $A=A_{2}=M=1$ and $B=0.1635$ \\
Weight of capital in produc. func. & $\alpha=0.325$ \\
\hline
\end{tabular}

Table 3 below presents the values of our economic variables in the three balanced growth paths. The interior, saddle-path stable equilibrium is denoted by BGP2. The interior, unstable equilibrium is denoted by BGP3, and the non-interior, saddle-path stable equilibrium by BGP1.

Table 3. Balanced growth paths for the baseline economy

\begin{tabular}{llll}
\hline \hline & BGP1 & BGP2 & BGP3 \\
\hline \hline Growth rate & 0.00000 & 0.01800 & 0.02814 \\
Unemployment rate & 0.03536 & 0.03030 & 0.01620 \\
Unemployment duration & 19 weeks & 16 weeks & 8 weeks \\
Labor-capital ratio & 0.15891 & 0.20705 & 0.23630 \\
Capital share & 0.36657 & 0.36000 & 0.35740 \\
Wage rate & 1.13506 & 1.04844 & 1.02553 \\
Rate of return on capital & 0.05500 & 0.07300 & 0.08314 \\
\hline \hline
\end{tabular}

The relationship between our economic variables across the two stable balanced growth paths, BGP2 and BGP1, is consistent with the evolution observed in European countries. As documented by many authors, the increase in unemployment was accompanied by an increase in unemployment duration. Also, as documented by Blanchard (1997), whereas the capital share increased sharply with unemployment, the labor-capital ratio went down from the early 70's on. The values reported by this author for France show an increase in the capital share by $20 \%$, and a similar decrease in the labor-capital ratio between 1970 and 1995. Daveri and Tabellini (2000) present similar tendencies for other European countries. Our model thus successfully accounts for the qualitative evolution of 
unemployment, growth and capital accumulation in Europe. The observed transition in unemployment and growth rates can thus be interpreted as a switch from BGP2 to BGP1 triggered by the shock of the mid 70's. Of course, the zero growth rate in BGP1 should be viewed as a normalization rather than as a prediction of actual growth. A different normalization, which would render positive growth in BGP1, would consist in assuming that $A$ grows over time at an exogenous rate. Since our concern in this paper is with the effects of human capital, our normalization is more suitable for our purposes.

\subsection{The persistence of employment shocks}

Under multiplicity of balanced growth paths, a transient shock to employment or to either physical or human capital can have permanent effects on the unemployment and growth rates. If the shock places the economy in the stable manifold of a different balanced growth path, its effects will last until a new shock, or series of shocks, brings the economy back to the stable manifold of the original balanced growth path. In this section, we study the vulnerability of our economy to an employment shock. We assume that the economy is initially at the interior, saddle-path stable equilibrium, and we then ask the following question: How big a transient shock to the rate of employment destruction has to be in order to increase the natural rate of unemployment? This will give us a measure of the fragility of the stable equilibrium with low unemployment and high growth.

We assume an unexpected, one-time shock to the rate of job destruction at $t=0$. Then, we compute the minimum magnitude of this shock such that the unemployment rate permanently increases to the level in BGP1. Technically, this exercise amounts to computing the distance from BGP2 to the frontier of its stable manifold. More specifically, we compute the level of employment in the frontier of the stable manifold where the physical-to-human capital ratio is the same as in BGP2. Then, we calculate the percentual change with respect to employment in BGP2. Since our model has two state variables, $x$ and $n$, and two stable balanced growth paths, we know that their stable manifolds must be separated by the unidimensional stable manifold of BGP3. This latter manifold is computed backward until we reach the physical-to-human capital ratio of BGP2. 
Following this procedure, and using the parameter values of our baseline economy, we computed the minimum shock to the rate of job destruction, $\lambda$, needed to yield a permanent increase in the natural rate of unemployment. We found that this shock is 0.01406 . That is, if employment falls by more than $1.4 \%$, the economy will converge to BGP1; for smaller shocks the economy will converge back to its original equilibrium, BGP2.

\section{Unemployment Policies and Vulnerability to Employment Shocks}

\subsection{Unemployment Benefits}

In this section we analyze the effects of an unemployment benefits program both on the long-run equilibrium and on its vulnerability to employment shocks. Our main finding is that a given shock to employment can result in a permanent increase in the natural rate of unemployment, and that the higher the level of unemployment benefits, that smaller the magnitude of the shock needed to bring about such an increase. In the light of this result, we can explain the marked difference in unemployment dynamics in Europe and the U.S. after the employment shock of the mid 70's in terms of their differences in unemployment benefits.

The literature on unemployment benefits has identified two main channels through which unemployment compensation can affect the allocation of resources in the economy, and therefore unemployment and production in equilibrium. First, a number of authors [e.g., Coe and Snower (1996) and Pissarides (1997)], have emphasized the disincentive effects introduced by unemployment compensation policies. The main argument is that these policies, by subsidizing unemployment, increase the reservation wage of unemployed workers, and therefore unemployment duration. When these disincentive effects are assessed in calibrated models, a large increase in unemployment and a contraction in output are typically found. These results have led to some authors to conclude that the differences between U.S. and European unemployment could be explained solely on the ground of unemployment policy differentials. However, as was pointed out above, the empirical 
evidence does not support this hypothesis, since high unemployment benefits in Europe were already present when unemployment was low.

A second strain of this literature has emphasized the positive effects of unemployment benefits when workers are risk averse or when markets are incomplete. In this regard, Acemoglu and Shimer (1999) show that with risk-averse workers a positive level of unemployment insurance is required to maximize output. Easley, Kiefer and Possen (1985) show the existence of potential welfare gains from unemployment compensation in an economy with incomplete markets.

Since our assumption of perfect risk sharing removes all uncertainty from the household maximization problem, our analysis of unemployment benefits sets aside the role played by these benefits in alleviating the effects of uncertainty. As the first group of authors mentioned above, our analysis focuses entirely on the distortions introduced by unemployment benefits on the relative price of different activities. We disentangle the equilibrium effects of these distortions, and find that unemployment benefits can increase the growth rate and reduce unemployment, at the cost of increasing the vulnerability to employment shocks. The way in which we introduce unemployment compensation policies captures the most salient features of unemployment programs in developed economies, both on the benefits side and on the funding side.

Regarding benefits to unemployed workers, one of the features of most unemployment programs in Europe and elsewhere is the existence of unemployment benefit replacement rates that decrease with the unemployment spell. Benefits entitlements before taxes for OECD countries, as measured by OECD (1996) for different duration categories, show a sharp decline with the unemployment spell. In France the replacement rate for a single unemployed worker goes from the $58 \%$ in the first year to a $40 \%$ in the second and third year, and to a $25 \%$ in the fourth and fifth year. In Spain these rates are $65 \%, 30 \%$ and $0 \%$ respectively. Sweden has $76 \%, 6 \%$ and $0 \%$, respectively. Exceptions to this rule are Denmark, where replacement rates are constant at $71 \%$ for the three duration categories; and the U.K. with 18\%, 19\% and 19\%, respectively. Declining replacement rates are aimed at the correction of the moral hazard problems inherent to the unemployment benefits system. Shavell and Weiss (1979) show that the gradual decrease in benefits provides the 
right incentives to alleviate these problems.

We introduce this feature of the unemployment program by writing the replacement rate as $\frac{\phi}{u d(t)}$, where $\phi>0$ is a constant, and $u d(t)=\frac{1}{m(t)}$ is the unemployment duration. Regarding the funding side of the program, we assume that the representative family pays taxes on income from wages and unemployment benefits ${ }^{5}$ at a rate given by $\tau(t)$. The budget constraint of the family is then given by,

$$
c(t)+\dot{k}(t)=r(t) k(t)+(1-\tau(t))\left(w(t) n(t) h(t)+\frac{\phi}{u d(t)} w(t) u(t) h(t)\right)+\pi(t) .
$$

The income value of an occupied job for the family depends on the labor income tax and the unemployment compensation. A new family member at work means one less unemployed person in the family. This amounts to a loss in unemployment income of $\phi m(t) \omega(t) h(t)$. The new worker must pay wage taxes of $\tau \omega(t) h(t)$. Hence, the value of an occupied job for the family solves the following arbitrage condition,

$$
r(t) W(t)=\omega(t) h(t)[1-\tau(t)][1-\phi m(t)]-(m(t)+\lambda) W(t)+\dot{W}(t) .
$$

The wage rate that solves the bargaining problem, (3.13), is now given by,

$$
\omega(t)=\frac{p}{1-(1-p) \tau(t)} F_{n h}[k(t), n(t) h(t)]+\frac{1-p}{1-(1-p) \tau(t)} A_{2} .
$$

We assume that the unemployment program is self-financing. That is, total benefits paid to the unemployed equal total revenues from taxation. This condition imposes the following relationship between $\tau(t)$ and $\phi$,

$$
\tau(t)=\frac{\phi u(t)}{\phi u(t)+n(t) u d(t)} .
$$

Although the effects of introducing unemployment benefits in an originally undistorted economy are difficult to figure out analytically, we can outline some of these effects as follows. On the one hand, for given matching, wage and tax rates, the expected value

\footnotetext{
${ }^{5}$ The issue of whether or not unemployment benefits should be treated as taxable income has been a subject of debate in many countries. For example, in the U.S. these benefits were not taxed until 1979.
} 
from unemployment is given now by $m(t) W(t)+(1-\tau(t)) \phi m(t) \omega(t) h(t)$, as opposed to $m(t) W(t)$ in the economy with no benefits. From household production the family gets $A_{2} h(t)$. Since in an interior equilibrium we have,

$$
m(t) W(t)+(1-\tau(t)) \phi m(t) \omega(t) h(t)=A_{2} h(t)
$$

unemployment must go initially up in order to maintain unchanged the expected income value from unemployment.

On the other hand, unemployment benefits reduce after-tax wages. Although beforetax wages go up when the unemployment policy is implemented, the family is unable to maintain after-tax wages at previous levels as long as its bargaining power is less than one [see equation (4.3)]. Thus, the income value of employment goes down with unemployment benefits. These two effects -the increase in unemployment and the decrease in the income value of employment- are well known from the previous literature on labor search and benefits. However, the fact that investment in physical capital and investment human capital are endogenous variables in our model introduces a new feedback in the economy which is absent in most models of labor search with unemployment policies. The role played by human capital investment is especially important to understand the consequences of policies on the long-run equilibrium. Thus, since the value of employment decreases with unemployment benefits, the family will increase the ratio of household production to market production. Human capital investment will also increase, leading to a lower physical-human capital ratio in the long-run equilibrium. The higher longrun growth rate will yield a lower unemployment rate. It should be noticed that these arguments hold as long as the equilibrium in the economy with unemployment benefits is interior.

Unemployment benefits in our model affect not only the level of our economic variables in the long-run equilibrium but also its vulnerability to shocks. That is, they will change the way in which an economy responds to a given employment shock. As was pointed out above, the return to search includes now unemployment income (see the left-hand side of equation 4.5), which, through the dependency of $\tau(t)$ on $n(t)$ (given by equation 4.4), opens a new channel for the effects of employment shocks. Indeed, in the economy with 
benefits, a shock to employment has an additional effect on the return to search, and, consequently, on the differential of time productivity across activities. The increase in this differential will result in a higher vulnerability to shocks.

In order to assess the importance of these effects quantitatively, we use our baseline economy presented in the previous section and solve the model for different values of the replacement rate, $\phi$. The results are shown in Table 3 below. Our exercise focuses on the effects on the interior, saddle-path stable balanced growth path. The second and third rows show the effects of increases in $\phi$ on the growth and unemployment rates along the interior, saddle-path stable long-run equilibrium. The fifth and sixth rows show the effects of $\phi$ on the vulnerability of this equilibrium to employment shocks. The fith row gives the magnitude of the shock to $\lambda$ needed to bring about a permanent increase in unemployment. The sixth row shows the shock in the unemployment rate implied by that shock to $\lambda$. It is clear from this table that the consequences of an employment shock strongly depend on the level of benefits paid to unemployed workers. Thus, a transient shock to the rate of job destruction by a $1.3 \%$ would cause a permanent increase in unemployment in the economy with unemployment benefits, but only a temporary increase in the economy with no benefits.

Table 4. Unemployment benefits and the response to an employment shock

\begin{tabular}{lcccccl}
\hline \hline$\phi$ & 0 & 0.001 & 0.003 & 0.005 & 0.007 & 0.01 \\
\hline Growth rate & 0.01800 & 0.01819 & 0.01859 & 0.01903 & 0.01952 & 0.02043 \\
Unemp. rate & 0.03030 & 0.03010 & 0.02965 & 0.02914 & 0.02856 & 0.02746 \\
Equilibrium Vulnerability & & & & & & \\
Min. shock to $\lambda$ & 0.01406 & 0.01297 & 0.01109 & 0.00887 & 0.00636 & 0.00162 \\
Implied shock in ur & 0.24982 & 0.23255 & 0.19641 & 0.15826 & 0.11632 & 0.03053 \\
\hline \hline
\end{tabular}

\subsection{Unemployment Benefits with Endogenous Vacancies}

In our previous analysis of the dynamic effects of unemployment benefits, vacancies were held fixed at the exogenous level $\hat{v}$. Indeed, since we maintained this assumption 
throughout the paper, our analysis relied exclusively upon supply considerations. In this section we endogenize the determination of vacancies in order to show that our results are robust to changes in the labor demand. We show that unemployment benefits increase the vulnerability of the economy to shocks, regardless of the cost function assumed to open a vacancy.

If we denote the cost of opening a vacancy by $D(t)$, the firm chooses the level of vacancies to maximize (3.10), where the current flow of profits is now given by,

$$
\pi(t)=F[k(t), n(t) h(t)]-(r(t)+\delta) k(t)-\omega(t) n(t) h(t)-D(t) v(t)
$$

Profits maximization imposes that the expected value of opening a vacancy must equal its cost,

$$
J(t) \mu(t)=D(t)
$$

In the literature, the cost of opening a vacancy is related to the level of some economic variable. If the concern is with the long-run equilibrium, the common assumption is to make $D(t)$ proportional to the level of productivity. If the concern is with business cycles, then it is made proportional to wages. Here we solved the model under three assumptions on $D(t)$ : proportionality to output, to wages and to the stock of capital. Since the results are not significantly different across these three specifications of $D(t)$, we limit our presentation to the case in which $D(t)$ is proportional to output, say $\psi F(k, n h)$.

In order to compute the economy's vulnerability we proceed as follows. We use the parameter values of our benchmark economy and replace $\hat{v}$ by the value of $\psi$ that renders the values of the interior, stable balanced growth path. This value of $\psi$ is 0.182 . Then, we vary the replacement rate and compute the minimum shock to $\lambda$ that would lead the economy to BGP1. Our results show that the effects of $\phi$ on the vulnerability of the equilibrium are not qualitatively different from those found in the economy with fixed vacancies. For example, whereas in the model with exogenous vacancies an increase in the replacement rate from 0.001 to 0.003 reduces the minimum shock to $\lambda$ by a $14 \%$, in the model with endogenous vacancies the minimum shock decreases by a $9 \%$. Similar results are found for further increases in the replacement rate. Overall, higher replacement rates 
increase the vulnerability of the economy to employment shocks even when we allow for changes in the labor demand function.

\section{Conclusions}

The analysis presented in this paper sheds new light on the long-standing European unemployment puzzle. That is, why unemployment rates have evolved so differently in Europe and the U.S. Our explanation relies on the interaction between shocks and labor market institutions. There are two main results that we would like to highlight. First, in a multisector economy with frictional unemployment, the natural rate of unemployment depends on the history of unemployment. We show that this result emerges under completely standard functions for utility, production and matching. Second, unemployment benefits make more likely that a given shock to employment result in a permanent increase in the unemployment rate.

A first implication of our results is that a policy of moderate unemployment benefits is not always bad for unemployment. Indeed, in economies with low turbulences and low shocks to employment, a policy of moderate unemployment benefits can help to reach low and sustained rates of unemployment. On the contrary, in economies with high employment shocks, unemployment benefits will bring high rates of unemployment. Although we did not carry out a welfare analysis of unemployment benefits, it may very well be, however, that there are substantial welfare improvements to be obtained from cutting down replacement rates. In a world with recurrent shocks to employment, the lower the level of unemployment benefits, the lower the volatility of consumption over the business cycle. By the concavity of the utility function this may result in a gain in the level of welfare. A second implication of our results is that the solution to the unemployment problem in Europe does not rely on the reduction of unemployment benefits. As a matter of fact, pre-shock unemployment rates could not be attained by simply lowering replacement rates. This is a consequence of the hysteresis property of unemployment. Only labor market reforms that place the current level of unemployment inside the stable manifold of a long-run equilibrium with low unemployment can restore pre-shock unemployment 
rates. Hence, labor market reforms aimed to reduce unemployment should target different labor market institutions, such as firing restrictions or wage setting institutions. The issue of complementarities in policy reforms is also crucial in this context. It should be clear from our analysis that changes in other labor market institutions may change the way in which unemployment benefits affect vulnerability.

Although our analysis of labor market institutions was restricted to unemployment benefits, our framework is suited to asses the role played by a large array of such institutions. We can easily introduce taxes on labor, and study its effects on the economy's vulnerability to shocks. According to Daveri and Tabellini (2000), high taxes on labor are to be blamed for the increase in European unemployment. Their results indicate that the rise of labor taxes by a $10 \%$ can account for a $4 \%$ increase in European unemployment. Our framework can also be used to evaluate the effects of government expenditure in commodities. Den Haan et al. (2001) claim that this type of expenditure has a non-negligible negative effect on the rate of unemployment. Another type of public policies that would be worth investigating are those related to the profile of unemployment benefits along the unemployment spell. In the last few years, some European countries have increased the steepness of the replacement rates profile. In order to encompass the analysis of this policy in our framework, we only need to rewrite the replacement rate so as to imprint a higher order of convergence. Public policies addressed to improve the efficiency of labor search were also widely implemented. In our framework this policy amounts to transforming the rate at which the unemployed is matched with a vacancy in a function of the services provided by the government. 


\section{Appendix}

The first-order conditions for the household problem are:

$$
\begin{aligned}
\frac{\gamma}{c(t)+c_{h p}(t)} & =\nu_{2}(t) \\
\nu_{1}(t) m(t) & =\nu_{3}(t) B h(t) \\
\frac{\gamma A_{2}}{c(t)+c_{h p}(t)} & =\nu_{3}(t) B \\
\frac{(1-\gamma)}{L(t)} & =\nu_{3}(t) B h(t)
\end{aligned}
$$

where $\nu_{1}(t), \nu_{2}(t)$ and $\nu_{3}(t)$ denote the shadow prices for employment, physical and human capital, respectively.

Equation (6.1) is the Euler equation, which determines the optimal allocation of income between consumption and investment; equations (6.2), (6.3) and (6.4) give the optimal allocation of time between labor search, home production, leisure and education.

From the arbitrage conditions, shadow prices for employment, physical and human capital must satisfy the following conditions,

$$
\begin{aligned}
& \dot{\nu}_{1}(t)=\nu_{1}(t)[\rho+\lambda+m(t)]-\nu_{2}(t) \omega(t) h(t) \\
& \dot{\nu}_{2}(t)=\nu_{2}(t)[\rho-r(t)] \\
& \dot{\nu}_{3}(t)=\nu_{3}(t)[\rho-B l(t)-B e(t)]-\nu_{2}(t) \omega(t) n(t) .
\end{aligned}
$$

The income value of an occupied job for the household, $W$, is given by the ratio $\frac{\nu_{1}(t)}{\nu_{2}(t)}$, which, after taking the derivative with respect to time, gives equation (3.6) in Section 2.

Proof of Proposition 2.1: Assume that the system of equations (3.16)-(3.23) contains two interior balanced growth paths with $\left\{g_{1}, u r_{1}, u d_{1}, x_{1}\right\}$ and $\left\{g_{2}, u r_{2}, u d_{2}, x_{2}\right\}$. Where $u r$ is used to denote the unemployment rate. We show that if $g_{1}>g_{2}$, then $u r_{1}<u r_{2}$, $u d_{1}>u d_{2}$ and $x_{1}>x_{2}$. 1) Let us write the unemployment rate as a function of the growth rate. From equations (3.17), (3.20) and (3.21) we can write $u$ as a function of $g$, which we denote by $u(g)$. Similarly, from equation (3.16) we obtain $n$ as a function of $g$, 
say $n(g)$. The unemployment rate is then

$$
u r(g)=\frac{u(g)}{n(g)+u(g)} .
$$

Taking derivatives with respect to $g$, it yields,

$$
\frac{d u r}{d g}=\frac{d u}{d g}\left[M_{0} \hat{v}^{\eta} u^{1-\eta} \frac{\eta}{\lambda}\right]
$$

Since $\frac{d u}{d g}<0$, it follows that $\frac{d u r}{d g}<0$.

2) Unemployment duration, $u d$, can be expressed as a function of $g$ as $\frac{u(g)}{M \hat{v}^{\eta} u(g)^{1-\eta}}$. As $\frac{d u}{d g}<0$, it follows that $\frac{d u d}{d g}<0$.

3) The labor-capital ratio is $\frac{n h}{k}$, which has been denoted by $x$. Differentiating both sides of equation (3.20) with respect to $g$, we obtain

$$
\frac{d x}{d g}=\frac{\left(\alpha+(1-\alpha) x^{\sigma}\right)^{\frac{2 \sigma-1}{\sigma}} x^{1-\sigma}}{(1-\sigma)(1-\alpha) \alpha A}>0
$$




\section{References}

[1] Acemoglu, D., (2000), "Credit Market Imperfections and Persistent Unemployment," European Economic Review, 45, pp. 665-679.

[2] Acemoglu, D. and R. Shimer, (1999), "Efficient Unemployment Insurance," Journal of Political Economy, 107, pp. 893-928.

[3] Balakrishnan, R. and C. Michelacci, (2001), "Unemployment Dynamics Across OECD Countries," European Economic Review, 45, pp. 136-161.

[4] Blanchard, O., (1997), "Revisiting European Unemployment: Unemployment, Capital Accumulation and Factor Prices," Twenty Eighth Geary Lecture.

[5] Blanchard, O. and P. Diamond, (1989), "The Beveridge Curve," Brookings Papers on Economic Activity, 1, pp. 1-60.

[6] Blanchard, O. and L. Summers, (1986), "Hysteresis and the European Unemployment Problem," NBER Macroeconomics Annual, 1, pp. 15-78, Stanley Fisher (editor), MIT press.

[7] Blanchard, O. and J. Wolfers, (2000), "The Role of Shocks and Institutions in the Rise of European Unemployment: The Aggregate Evidence," Economic Journal, 110, pp. 1-33.

[8] Coe, D. and D. Snower, (1996), "Policy Complementarities: The Case for Fundamental Labor Market Reform," Birkbeck College, Discussion Paper 9625 .

[9] Daveri, F. and G. Tabellini, (2000), "Unemployment, Growth and Taxation in Industrial Countries," Economic Policy, 15, pp. 47-104.

[10] Den Haan, W.J., C. Haefke and G. Ramey, (2001), "Shocks and Institutions in a Job Matching Model," NBER working paper 8463. 
[11] Easley, D., Kiefer, N. and U. Possen, (1985), "An Equilibrium Analysis of Optimal Unemployment Insurance and Taxation," Quarterly Journal of Economics, 100, pp. 989-1010.

[12] Eichenbaum, M. and L. P. Hansen, (1990), "Estimating Models with Intertemporal Substitution Using Aggregate Time Series Data," Journal of Business and Economic Statistics, 8, pp. 53-69.

[13] Hart, O., (1982), "A model of imperfect competition with Keynesian features," Quarterly Journal of Economics, 97, pp. 109-138.

[14] Hosios, A. J., (1990), "On the efficiency of matching and related models of search and unemployment," Review of Economic Studies, 57, pp. 279-98.

[15] Howitt, P. and P. McAfee, (1987), "Costly search and recruiting," International Economic Review, 28, pp. 89-107.

[16] Ljungqvist, L. and T. Sargent, (1998), "The European unemployment dilemma," Journal of Political Economy, 106, pp. 514-550.

[17] Mortensen, D., (1989), "The Persistence and Indeterminacy of Unemployment in Search Equilibrium," Scandinavian Journal of Economics, 91, pp. $347-370$.

[18] Mortensen, D., (1999), "Equilibrium Unemployment Dynamics," International Economic Review, 40, pp. 889-914.

[19] OECD, (1996), "Measures of Replacement Rates for the Purpose of International Comparisons: A Note," OECD Economic Studies, 26, pp. 99-117.

[20] Pissarides, C., (1986), "Unemployment and Vacancies in Britain," Economic Policy, III, pp. 489-559.

[21] Pissarides, C., (1992), "Loss of Skill During Unemployment and the Persistence of Employment Shocks," Quarterly Journal of Economics, 107, pp. 1371-91. 
[22] Pissarides, C., (1997), "Impact of Employment Tax Cuts on Unemployment and Wages: The Role of Unemployment Benefits and Tax Structure," Center for Economic Performance, London School of Economics, Working Paper.

[23] Saint-Paul, G., (1995), "The High Unemployment Trap," Quarterly Journal of Economics, pp. 527-551.

[24] Shavell, S. and L. Weiss, (1979), "The Optimal Payment of Unemployment Insurance Benefits over Time," Journal of Political Economy, 87, pp. 13471362 . 


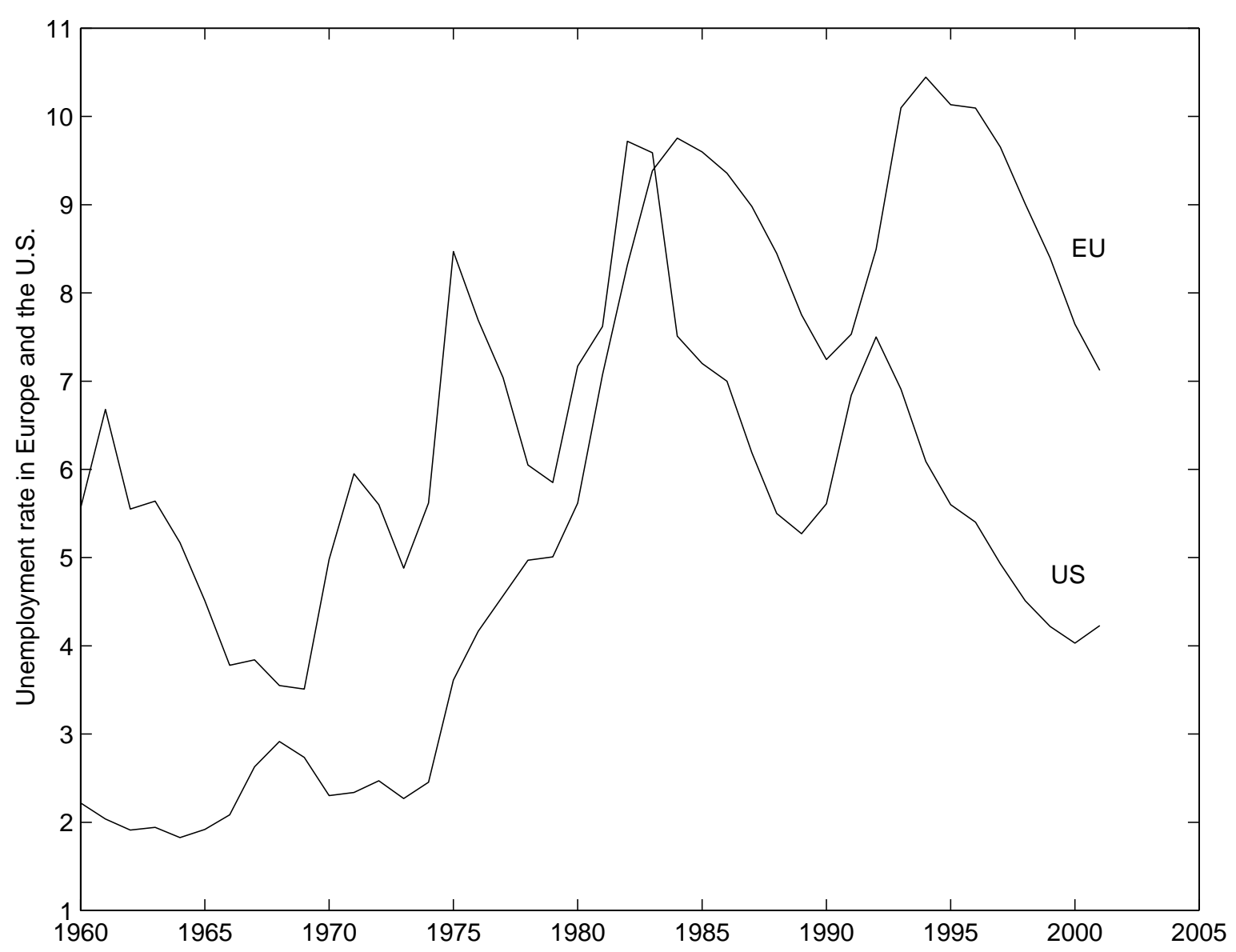

Figure 1: Unemployment rate in Europe and the U.S. for 1960-2000. The European countries considered in this paper are: Belgium, Denmark, France, Germany, Greece, Ireland, Italy, Netherlands Portugal, Spain, Sweden and United Kingdom. 

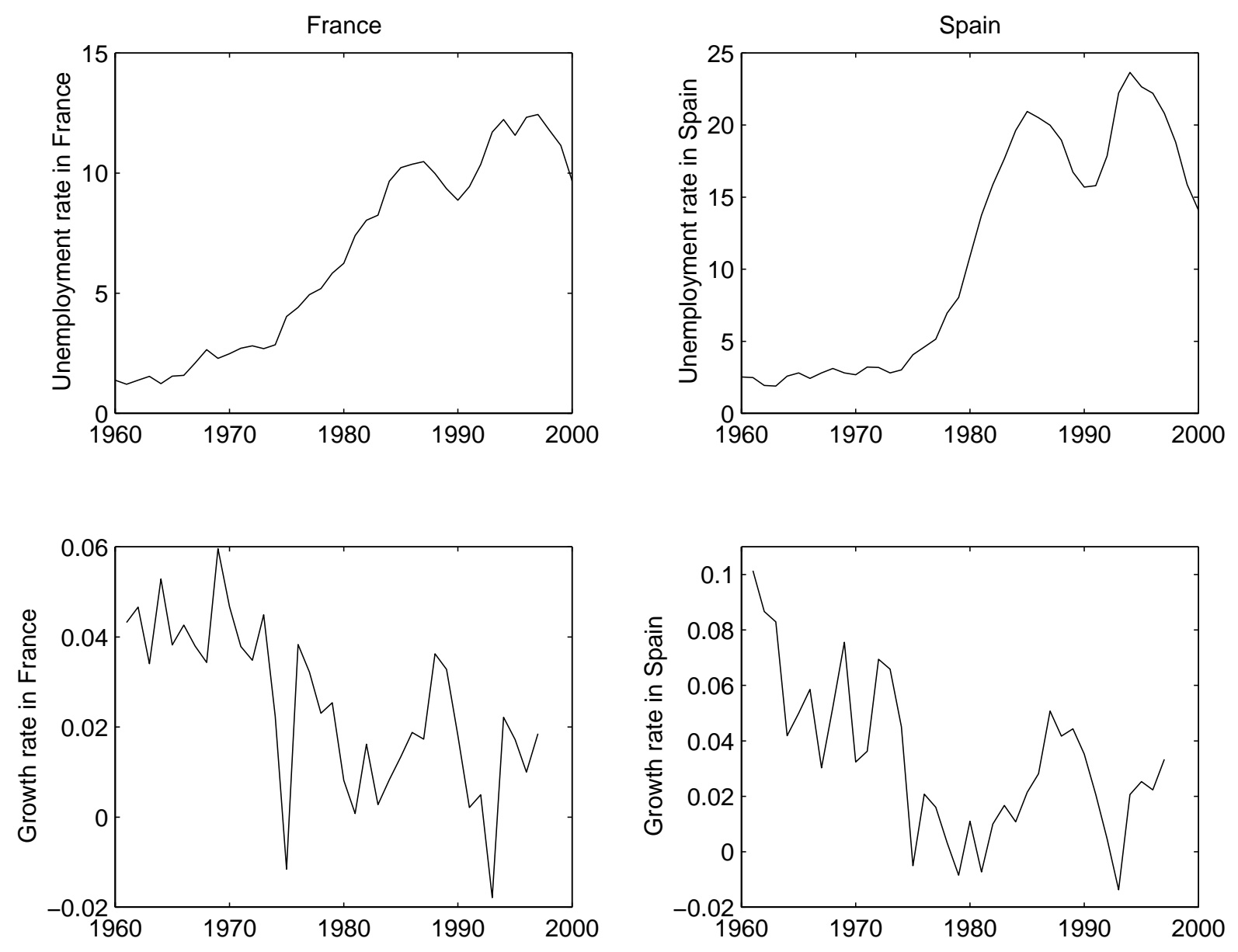

Figure 2: Unemployment and growth in France and Spain. 